\title{
TURKISH BATH CULTURE IN HUNGARY
}

\author{
Henrietta BODOLAI ${ }^{1}$, Balázs KÓSA², Tamás MOLNÁR ${ }^{3}$, Gábor Arnold SZÜCS ${ }^{4}$ \\ University of Pécs, Faculty of Engineering and Information Technology, Department of Visual Knowledge, \\ Pécs, Hungary \\ ${ }^{1}$ bodolai.henrietta.heni@gmail.com \\ ${ }^{2}$ kosa.balazs.84@gmail.com \\ ${ }^{3}$ tmolnar@mik.pte.hu \\ ${ }^{4}$ szucs.gabor.arnold@gmail.com
}

\begin{abstract}
Just like at the Romans, the bath was the main venue of everyday life for the Turkish people as well. Besides exchanging recipes, women gave advice to each other, the men disputed important issues and often kept pre arranged marriages here. You were only allowed to pray, when you were sufficiently cleaned. Of course, it is not insignificant that the construction of baths was in many cases intended to promote material well-being, as they were usually built by senior executives who influenced the satisfaction of their followers in a very positive direction. Generally speaking, these baths were free for the reasons mentioned above, indicating to everyone that the builder was a wealthy man.
\end{abstract}

Keywords: turkish, Pécs, Monumental building, ilidzse, hammam.

\section{Historical overview}

Water has been significant in people's lives since ancient times, since there are plenty of living creatures found in the water which our ancestors known to be nutritious and it is also a perfect transportation surface. It already had an important role in ancient cults. Almost all religions mention and/or use bathing. Most of the time, besides the body, it symbolizes the purification of the soul, and perhaps this is what spawned the bath culture. This is how Writh István writes about it in his publication called Bathculture. Baths in the ancient East had a cultural and therapeutic role. The most famous biblical Bethesda was built in Jerusalem above a lake, which was fed by healing water, built five pillars, the patients were lying here waiting for the angel of the Lord to land the lake to stir up the water and healing the first ones that step into the water. Perhaps the water that was repeatedly ruptured magnified the affect. Traditionally, the paschal lambs were bathed here before the temple ceremony. Even before our era it was considered a sacred place. That was the place Jesus performed the cure of the crippled man. "[1] Of course, it has outgrown itself and is not just about different religions anymore. In our present it exists as fun, relaxation, sports, healing, basically in our everyday lives.

Turkish culture has a major role in the history of its development. To this day, we have many baths of turkish style in nearly every area of the country. Because of their unusual appearance, it is easy to notice, but in today's fast-paced world, most of the people walk past them, so we decided to highlight such a pearl from the sea of houses in our home town, Pécs.

The basic rule of the Turkish baths - in many places even today - is that women and men can not stay in the building at the same time, so there were two possibilities. One is that the week was divided into days, when only ladies, and days when only men could visit these types of institutions. The other method was that so-called twin baths were created. The Memi Pasha bath in Pécs 
was part of the latter arrangements, which we will discuss in detail in our following study. We distinguish two types according to their structure and function to Turkish baths. One is ilidzse, that is, thermal, and the other is the hammam, that is, the steam bath. Essentially, the type of a given bath is determined by the environmental conditions around it. If there was a source of thermal water in the vicinity, then ilidzse was usually found. In this case, they not only circulated this water in the wall and floor for heating the bath, but in the circular or regular polygonal designed hot room a pool was built. Where no source of thermal water was available, they were forced to heat the bath with a boiler, and circulate the hot air there. In this case a pool was not possible. They built wall-fountains and wash basins, which had running water, that they poured to the floor, to counteract the heat with the generated steam. According to their construction, a hamman was built in three parts: The entrance was the changing room itself. This was followed by the temporary room where there were usually benches arranged in a circle, intersected by a few fountains that they used to water their own bodies and the heated walls and floor. The next room of traditional steam baths was the hot room where the rituals were taking place. In the middle of the room, lay a stone sheet on which the clients received the baths and the massages, treatments. In addition, along the walls there were benches and wall-fountains for cooling. In the steam baths, due to the lack of thermal water, there was a need for a boiler room and reservoir, which was usually separated from the bath, from where the hot air flowed into the heating system under the floor.

\subsection{Memi Pasha's bath - story}

Evlia Cselebi story teller, who traveled a great deal in the areas of Turkish occupation at that time, describes three baths here in Pécs, one of it is Ferhad Pasha's bath (no longer visible), another is Kashim Pasha's Bath (also not remained) and the third is Memi Pasha's Bath.[2] The latter was destroyed approximately in the 1880s, but later when they explored the Sallai Street, they discovered a part of the twin bath, which is a rectangular section of $29,13 \times 11,6 \mathrm{~m}$. This funcioned as a hammam, in other word a steam bath because there is no thermal water nearby. It was built around the second half of the 16th century, which was part of Memi pasa's külli (complex of sever- al buildings). It was located near the Szigeti gate inside the city wall, right next to the Franciscan Church (then Memi Pasha's Mosque). The excavation was carried out by Győző Gerő, „The excavated remains of the Memi Pasha's bath are elongated, square-shaped buildings, facing east-west, with a length of $29.13 \mathrm{~m}$ and a known maximum width of $11.60 \mathrm{~m}$. "[3]

After which a sectional reconstruction was made by Zoltán Dr. Bachman, who wanted to exhibit the originally found walls, floors and other related parts. In the foreground, for example, a hexagonal fountain was also displayed. Beside the walls, you can find the sitting benches and sofas that they could relax on. In the lukewarm room there are the wall-fountains, and also the aforementioned seating arrangements. The floor of the innermost hot room did not survived the time. During the excavation, only the lines on the walls and the pillars of the underfloor heating bricks could be seen, so they could only restore the condition, based on these guidelines. In addition, there were also wall-fountains and washing basins, from which they took the cold water in order to cool their heatened bodies, and also the most important part, which is the octagonal stone sheet on the floor where the guests were massaged at those times. In addition to the bathing rooms, the boiler and heating room's details were also exposed. This later served as an exhibition space. These rooms were covered by a dome filled with regular hexagonal openings. It symbolized the starry sky for them.

\section{Development concept}

In addition to the accurate documentation of the building's ruins and the geometrical mesuring, we felt that we should carry out a conservation and reutilization work at a conceptual level. We thought that it is important design a plan for the additional building, which, as a shell protects the remains, is not too aggressive but still has a sufficiently definite form to draw attention to the monument that dwindles in the streets of Ferencesek. It was also a conceptual point of view, that the age of the given monument should be clear for everyone, so we were thinking of characteristic motifs and mass designs. As a consequence, a metal structure has been placed under the glass cover, which weights on a protective layer of concrete on the walls, forming a facade that is noticeable, yet discrete. The basic shape of the structure's was inspired by a Turkish pattern 
and finally simplified to our version. The whole structure was covered with sand blasted glass, thus giving shelter for the reamains underneath and adding a mysterious apeal that reflets to the plain features of the hamam by imitating steam. Once we accomplised that the passers-by would want to know about the remains of the bath, and enter between the remaining walls, we needed a proper information medium. We have imagined a surface of glass with a pressure sensor, where the steps allow the special LED tiles to be switched on in a single field and thus reveal more information about the bath in different languages. The material of these tiles would be glass with sandblasting. The remaining glass would be clear glass that allows the remains to be visible, despite all the new

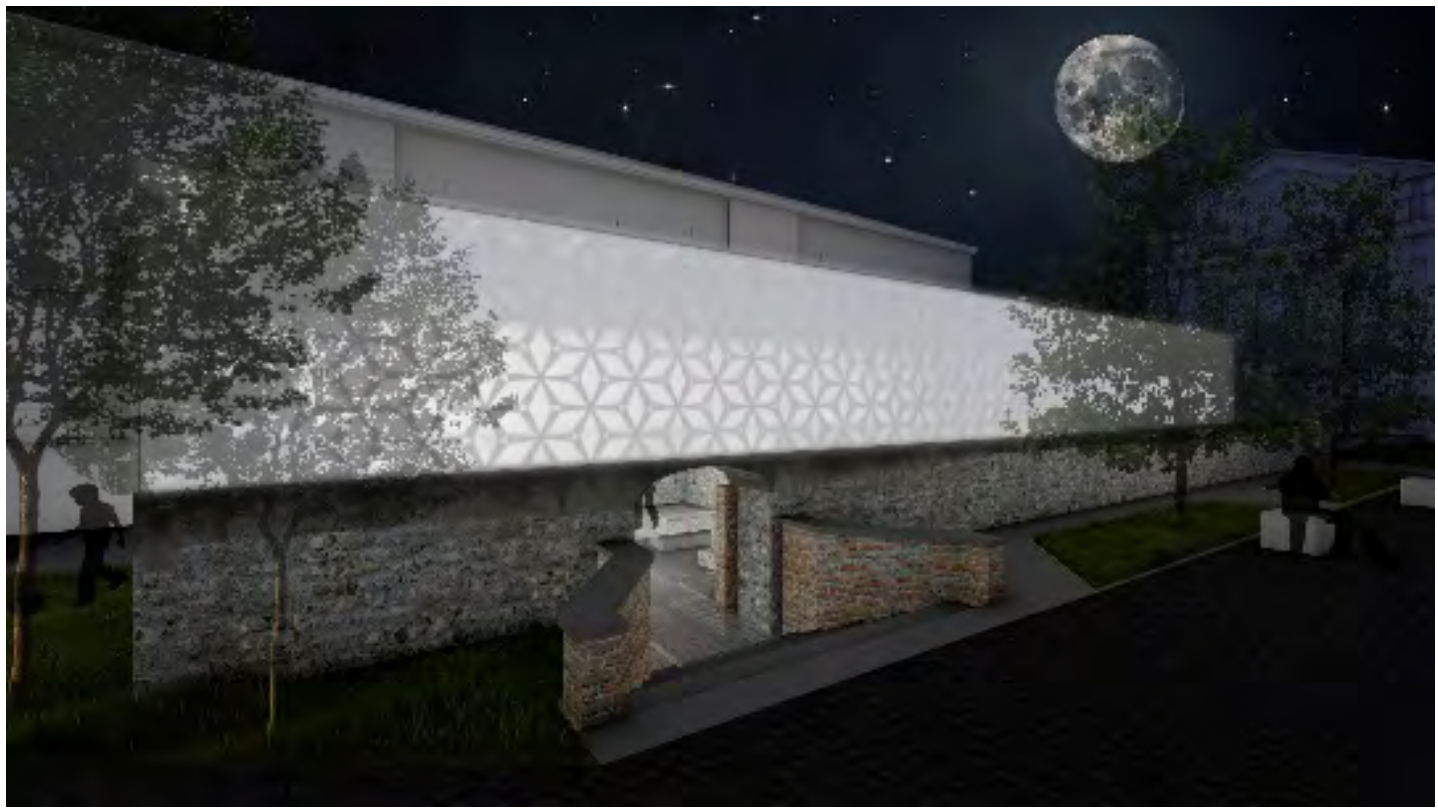

Figure 1. Conception plan night view visualization (self-made)

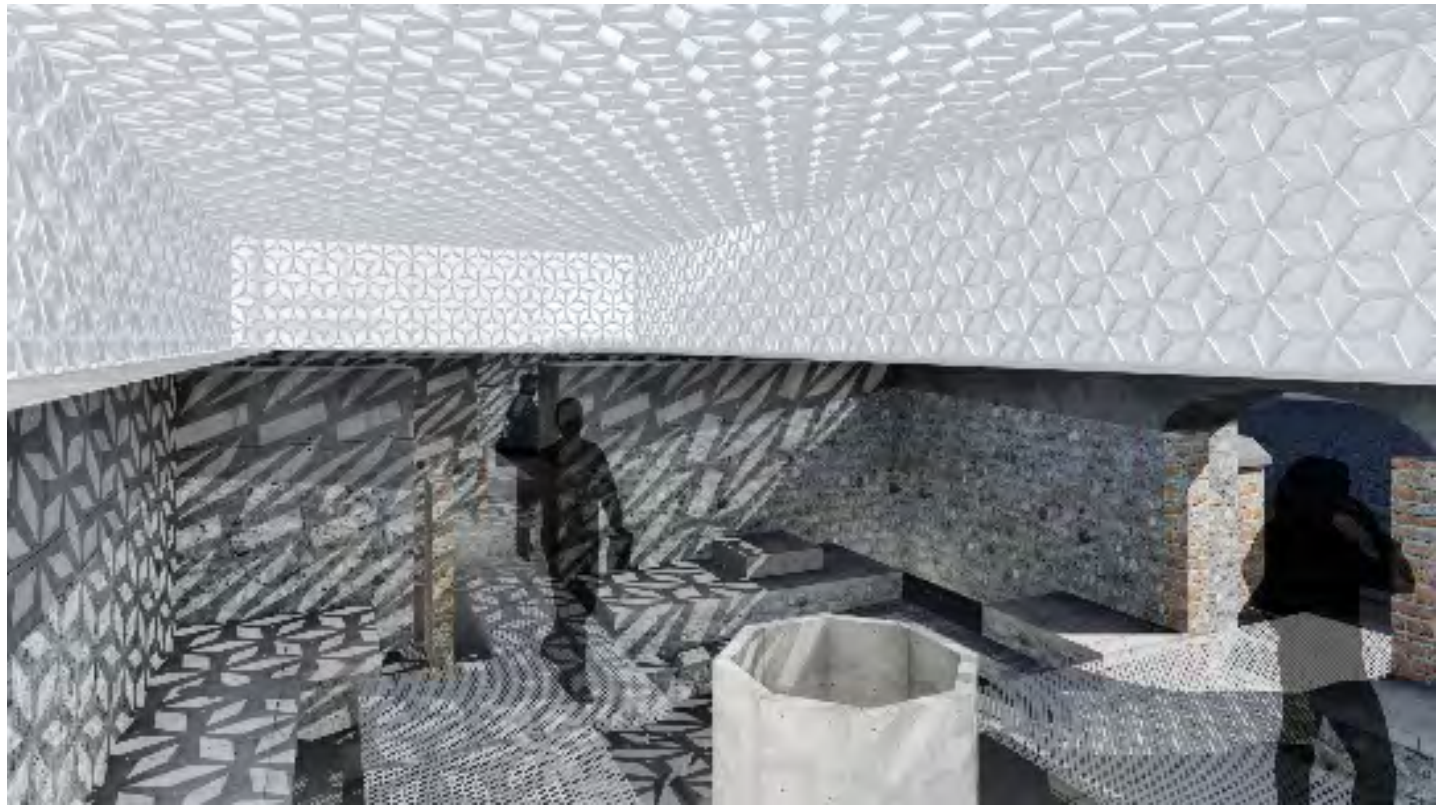

Figure 2. Indoors conception plan visualization (self-made) 
constructions. By means of these tools, we wanted to achieve an effect that leaves an impression in people, and they will want to find out more about other similar monuments later on.

\section{Conclusions}

In our opinion, getting to know the history of these baths, why we have done what we did since ancient times, for what kinds of reasons we use bathing, we would already say our research holds value. Compared to the history of the past times, we noticed that there is not so much difference between today's bath culture, seeing how respectfully they have been treating the remaining baths for the past centuries, till this day, trying to save and refurbish them. We can feel that this is just as important to today's man, than it was before. Of course, today the concept of bath culture is quite open and has entered the everyday life of our society. We think that our existing Turkish bath buildings need to be refurbished, because it is a signature of another culture, but on our paper.

\section{References}

[1] Wirth I.: Fürdőkultúra. Szent István Egyetem, Gödöllő, 2011.

[2] Evlia Cs., Karácson I.: Evlia Cselebi török világutazó magyarországi utazásai 1660-1664. Magyar Tudományos Akadémia, Budapest, 1904, 201.

[3] Gerő Gy.: A pécsi Memi pasa fürdő. Műemlékvédelem 31/2. (1987) 109-117.

http://www.virtualisregeszetsirok.hu/webimages/files/m093_k.pdf 